\title{
Pulse-Current Electrodeposition for Loading Active Material on Nickel Electrodes for Rechargeable Batteries
}

\author{
M. D. Becker, G. N. Garaventta, and A. Visintin \\ Instituto de Investigaciones Fisicoquímicas Teóricas y Aplicadas (INIFTA), Facultad de Ciencias Exactas, UNLP, CCT La Plata- \\ CONICET, Casilla de Correo 16, Sucursal 4, 1900 La Plata, Argentina
}

Correspondence should be addressed to M. D. Becker; dbecker@inifta.unlp.edu.ar

Received 25 January 2013; Accepted 18 February 2013

Academic Editors: X. He, B. Lakard, D. Silvester-Dean, and W. Xing

Copyright (C 2013 M. D. Becker et al. This is an open access article distributed under the Creative Commons Attribution License, which permits unrestricted use, distribution, and reproduction in any medium, provided the original work is properly cited.

\begin{abstract}
Although the pulse-current electrodeposition method is a commonly used technique, it has not been widely employed in electrode preparation. This method was applied to sintered nickel electrodes in a nickel salt solution containing additives. The active material that was obtained, nickel hydroxide, was studied using different characterization techniques. Electrodes impregnated with pulse current had higher capacity than those impregnated with continuous current. The active material is homogeneous and compact with optimum loading and good performance during discharge. These characteristics would provide a large amount of energy in a short time due to an increase in the electrode kinetic reaction.
\end{abstract}

\section{Introduction}

Nickel hydroxide has many applications in the positive electrodes of alkaline cells such as nickel cadmium (Ni-Cd), nickel hydrogen $\left(\mathrm{Ni}-\mathrm{H}_{2}\right)$, nickel metal hydride $(\mathrm{Ni}-\mathrm{MH})$, and nickel iron (Ni-Fe) cells [1-3].

The chemical pasting of a mixture of active material on a support conductor is used to prepare the positive electrodes of alkaline batteries [4]. This kind of electrode is used in the batteries of mobile phones, mp3s, emergency lights, and electric vehicles. Nickel hydroxide should have a homogeneous particle size and bulk distribution. Two methods are commonly used to obtain this kind of nickel hydroxide: indirect chemical precipitation and direct chemical precipitation. In both cases nickel hydroxide is obtained as a powder that then must be properly prepared to build the electrodes. For the manufacture of nickel hydroxide electrodes for use in high-performance batteries, such as nickel hydrogen batteries used as power source in space satellites, the impregnation technique used consists of the cathodic electrodeposition of sintered nickel plates. There are several variations of this technique such as (i) the Kandler process [5], which includes an electrochemical precipitation stage, working with a $0.3 \mathrm{M} \mathrm{Ni}\left(\mathrm{NO}_{3}\right)_{2}$ solution and an initial $\mathrm{pH}$ between 3 and 4 , which is adjusted with nitric acid, and (ii) the process developed by Pickett and Maloy [6], which applies the same principle, but using a nickel nitrate solution in alcohol, $\mathrm{pH}=3.5$. These are the impregnation processes that were taken as the basis to develop our technique for the preparation of nickel hydroxide electrodes for high discharge capacity and long service life. The different properties of the electrodes that make them superior are not yet well known in the literature [7-9].

When the electrode is charged, nickel hydroxide is oxidized to nickel oxyhydroxide. During discharge the reaction is reversed, and $\mathrm{Ni}(\mathrm{OH})_{2}$ has good cyclability and high energy density, both of which are important characteristics for alkaline batteries. To increase the energy density in each of these batteries, it is necessary to improve the performance of the positive electrode $[10,11]$. The electrochemical energy storage in nickel hydroxide electrodes is related to the reversible characteristics of the redox couple nickel hydroxide/ox hydroxide, and in this work we describe how the electrode preparation method influences battery performance.

The $\mathrm{Ni}(\mathrm{OH})_{2} / \mathrm{NiOOH}$ charge-discharge process is believed to be a solid-state, proton intercalation/deintercalation reaction [12], whereby both electrons and protons are exchanged and the processes are considered to be controlled by the bulk solid diffusion of protons [13]. If proton diffusion into the bulk solid phases was a slow process, $\mathrm{Ni}(\mathrm{OH})_{2}$ 
buildup on the surface of the active material would cause a significant rise in polarization for the charge reaction. The accepted scheme for the $\mathrm{Ni}(\mathrm{OH})_{2} / \mathrm{NiOOH}$ couple, which involves more than one phase, can be summarized as [14]

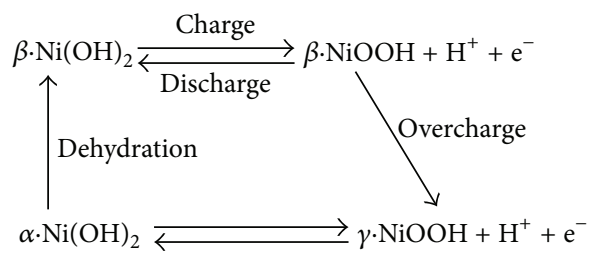

$\beta-\mathrm{Ni}(\mathrm{OH})_{2}$ has a well-defined crystalline structure and is the active material in chemically prepared nickel battery electrodes. In batteries, charging of the nickel hydroxide electrode involves the homogeneous solid-state oxidation of $\beta-\mathrm{Ni}(\mathrm{OH})_{2}$ to $\beta-\mathrm{NiOOH}$. Overcharging of $\beta-\mathrm{Ni}(\mathrm{OH})_{2}$, however, can lead to the formation of $\gamma$ - NiOOH.

The most widely used technique in the construction of electrodes for space battery applications is cathodic electrodeposition, where the precipitation occurs in one step [1419]. The sintered nickel plate support is immersed in an aqueous solution of $\mathrm{Ni}\left(\mathrm{NO}_{3}\right)_{2}(1.8 \mathrm{M})$ and a cathodic polarization current is applied. This produces an $\alpha-3 \mathrm{Ni}(\mathrm{OH})_{2} \cdot 2 \mathrm{H}_{2} \mathrm{O}$ film [20], but $\alpha-\mathrm{Ni}(\mathrm{OH})_{2}$ is unstable in alkaline media and is easily converted to $\beta-\mathrm{Ni}(\mathrm{OH})_{2}$. When the positive current passes through the electrolytic cell, the solvent supporting the electrolyte system releases hydroxide anions. This may occur by the direct evolution of hydrogen gas at the electrode (2) or by reduction of the nitrate ion (3).

These anions can be produced on the negative electrode by the electrolytic decomposition of water:

$$
2 \mathrm{H}_{2} \mathrm{O}+2 \mathrm{e}^{-} \longrightarrow \mathrm{H}_{2}+2 \mathrm{OH}^{-} \quad \mathrm{E}^{0}=-0.83 \mathrm{~V}
$$

or $\mathrm{OH}^{-}$ions are produced by direct $\mathrm{NO}_{3}{ }^{-}$reduction:

$$
\mathrm{H}_{2} \mathrm{O}+\mathrm{NO}_{3}{ }^{-}+2 \mathrm{e}^{-} \longrightarrow \mathrm{NO}_{2}{ }^{-}+2 \mathrm{OH}^{-} \quad \mathrm{E}^{0}=0.01 \mathrm{~V}
$$

An alternative reduction mechanism of nitrate to $\mathrm{NH}_{4}{ }^{+}$and $\mathrm{OH}^{-}$ions has also been discussed in the literature [21, 22] (4):

$$
\mathrm{NO}_{3}{ }^{-}+6 \mathrm{H}_{2} \mathrm{O}+8 \mathrm{e}^{-} \longrightarrow \mathrm{NH}_{4}{ }^{+}+10 \mathrm{OH}^{-} \quad \mathrm{E}^{0}=-0.12 \mathrm{~V}
$$

The reaction produces a hydroxide ion increase in the porous nickel plates, which then react with the nickel (5) present in the bulk solution to precipitate battery-active nickel hydroxide within the pores.

Interface. Consider

$$
\mathrm{Ni}^{+2}+2 \mathrm{OH}^{-} \longrightarrow \mathrm{Ni}(\mathrm{OH})_{2}
$$

Metallic nickel may also be deposited within the pores of the plate material. In this way, its presence would presumably remove the active material from the electrode:

$$
\mathrm{Ni}^{+2}+2 \mathrm{e}^{-} \longrightarrow \mathrm{Ni}^{0}
$$

During the immersion processes, $\mathrm{Ni}\left(\mathrm{NO}_{3}\right)_{2}$ solutions with lower concentrations of metal nitrate are added in order to incorporate additives such as $\mathrm{Cd}, \mathrm{Co}, \mathrm{Zn}$, or $\mathrm{Al}$ [23-29].

Pure $\mathrm{Ni}(\mathrm{OH})_{2}$ is essentially an electrical insulator, so the effects of coprecipitated cobalt hydroxide increase the conductivity [30-32]. The cobalt ion addition to the active materials shows how $\mathrm{Co}^{+2}$ changes its oxidation state to $\mathrm{Co}^{+3}$ during the charge-discharge cycle. $\mathrm{Co}^{+3}$ cannot be reduced during subsequent discharging. There are also papers that discuss the addition of cobalt to nickel hydroxide electrodes, where an increase in the conductivity and the oxygen evolution potential and a delay in the mechanical failure of the electrodes have been reported [12, 29].

The aim of the present work was to determine whether the application of an intermittent train of pulses improves the electrochemical performance of nickel hydroxide electrodes. Only a few papers in the literature have explored these properties [33-35] and we want to know whether the structure of nickel hydroxide, which was deposited by the train of pulses, was responsible for giving nickel hydroxide a discharge capacity close to the expected theoretical maximum value.

\section{Experimental}

2.1. Electrochemical Impregnation of Nickel Hydroxide. The impregnation consists of an electrochemical process in aqueous solution. During this process many parameters must be controlled to keep the impregnation results consistent.

The temperature was controlled automatically at $70^{\circ} \mathrm{C}$ with the heating circulator. The solution contains $1.8 \mathrm{M}$ nickel nitrate and $0.2 \mathrm{M}$ cobalt nitrate.

The sintered nickel plate was pretreated in boiling distilled water for $15 \mathrm{~min}$ and then heated at $350^{\circ} \mathrm{C}$ for $30 \mathrm{~min}$ in order to remove impurities.

The sintered nickel plate $\left(6.25 \mathrm{~cm}^{2}\right.$ and empty volume of $0.36 \mathrm{~cm}^{2}$ ) [36] was held in place by a Teflon fixture, maintaining the separation between the electrodes constant; also with this structure we ensured minimum current distribution over the working electrode. The electrolyte was magnetically stirred and heated on a hotplate, achieving a homogeneous concentration throughout the volume of the cell (Figure 1).

Continuous current was applied using $64 \mathrm{mAcm}^{-2}$ amplitude for $3 \mathrm{~h}$. The parameters of intermittent pulse trains were $64 \mathrm{mAcm}^{-2}$ amplitude; time ON: OFF is indicated in Table 1 and total time was $3 \mathrm{~h}$. The pulses were generated by GED-M1 LYP digital generator.

All electrochemical experiments were performed in a conventional glass cell in $6 \mathrm{M} \mathrm{KOH}$ solution that was prepared from AnalaR grade potassium hydroxide and twice-distilled water. The counterelectrode was a nickel mesh. A Hg/HgOss reference electrode in $6 \mathrm{M} \mathrm{KOH}$, which was the same as the measuring solution, was used as the reference electrode. Charge-discharge cycles at a $0.5 \mathrm{C}$ rate $(\mathrm{C}=$ theoretical capacity, $289 \mathrm{mAhg}^{-1}$ ) were performed (ARBIN BT 2000). All the potentials in this paper are referred to as the $\mathrm{Hg} / \mathrm{HgOss}$ electrode. The electrodes were discharged until $0.2 \mathrm{~V}$; this potential was considered $100 \%$ of state of discharge (SOD). 
TABLE 1: Main characteristics of $\mathrm{Ni}(\mathrm{OH})_{2}$ electrodes.

\begin{tabular}{|c|c|c|c|c|c|}
\hline Electrode/pulse (sec: sec) & $\begin{array}{l}\text { Theoretical capacity } \\
(\mathrm{mAh})\end{array}$ & $\begin{array}{c}\text { Discharge capacity } \\
(\mathrm{mAh})\end{array}$ & $\begin{array}{l}\text { Specific capacity } \\
\left(\mathrm{mAhg}^{-1}\right)\end{array}$ & $\begin{array}{c}\text { Utilization } \\
(\%)\end{array}$ & $\begin{array}{l}\text { Loading } \\
\left(\mathrm{gcm}^{-3}\right)\end{array}$ \\
\hline CP1 (on: 180/off: 90) & 188.7 & 135.1 & 206.9 & 71.6 & 1.74 \\
\hline CP2 (on: 90/off: 45) & 167.1 & 174.1 & 291.3 & 104.2 & 1.66 \\
\hline CP3 (on: 12/off: 6) & 202.9 & 203.2 & 289.2 & 100.2 & 1.94 \\
\hline CP4 (on: 6/off: 3 ) & 161.1 & 183.9 & 321.2 & 114.2 & 1.59 \\
\hline CC (continuous current) & 197.4 & 157.1 & 229.9 & 79.5 & 1.9 \\
\hline
\end{tabular}

$\left({ }^{*}\right)$ The theoretical capacity is calculated by considering the transfer of 1 electron $\left(289 \mathrm{mAhg}^{-1}\right)$ of active material.

$\left({ }^{a}\right)$ The discharge capacity values listed in Table 1 are at 70 charge/discharge cycles, 100\% SOD.

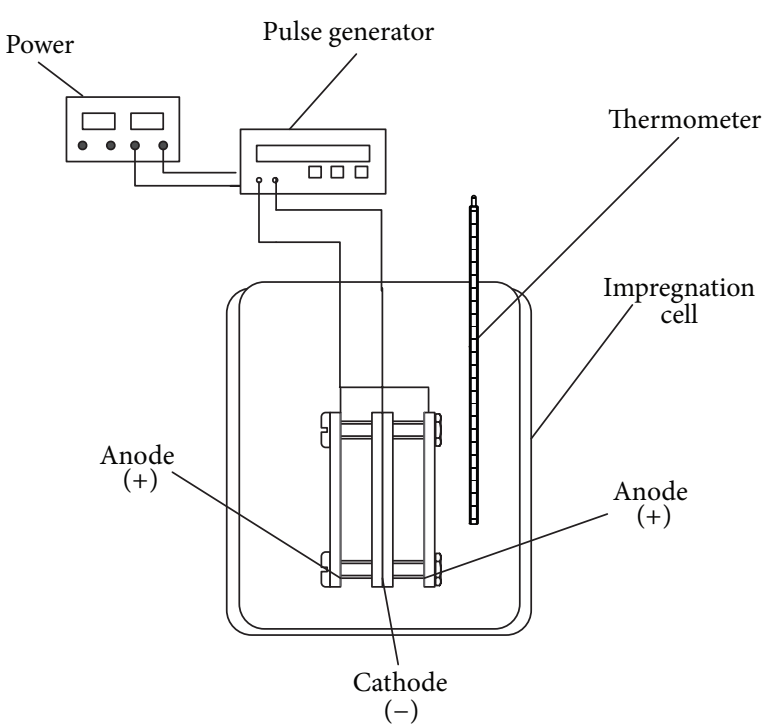

FIGURE 1: Impregnation cell assembly.

The morphology and chemical composition of the prepared nickel hydroxide electrode were characterized with a JEOL JSML5510LV scanning electron microscope (SEM) and by energy dispersive spectroscopy (EDS).

The main characteristics of the different electrodes are listed in Table 1.

\section{Results}

3.1. Galvanostatic Discharge Curve. After impregnation, the electrodes were rinsed in deionized water and formed using the Eagle-Picher formation procedure [37]. The procedure consisted of $51 / 2$ cycles beginning and ending with the discharge. Each cycle was $40 \mathrm{~min}$ long in $20 \%$ potassium hydroxide. For the first 4 cycles, the current was at a $3.4 \mathrm{C}$ rate. The current was reduced to $0.75 \mathrm{C}$ for cycle five and again reduced to $0.5 \mathrm{C}$ for the final half cycle. After that, the electrodes were cycled many times.

Figure 2 shows a contrast of the typical constant current discharge of the electrode impregnated with pulse current (CP3) and the electrode impregnated with continuous current (CC).

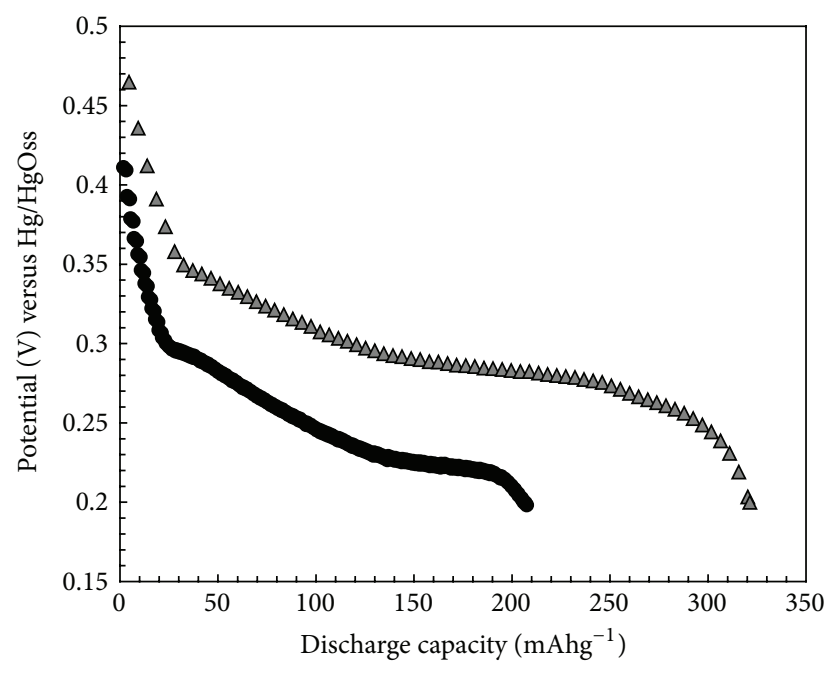

$\triangle$ Electrode CP4

- Electrode CC

FIGURE 2: Constant current discharge curves for electrodes impregnated with constant current and pulse current.

Besides having greater capacity than CC (Table 1), the plateau for CP3 is better defined and is shifted by about 25 to $50 \mathrm{mV}$ in the potential positive direction. This difference indicates that when the loading is high, the particles are not able to absorb the proton quickly; therefore, mass transport is the limitation. The higher the amount of active material is, the lower the active surface of the material results. Hence it is proton diffusion within the solid one that limits the speed of the reaction. For this reason, it has a greater ohmic drop.

3.2. Rate Capability. To study the performance of the electrodes, the response of the discharge capacity of the electrode versus different discharge currents was also taken into account. To estimate the electrode capacity, the discharge current values ranged from $\mathrm{C} / 20$ to $3 \mathrm{C}$ in order to observe the behavior of the electrode under strict discharge conditions and lower current values.

We used different discharge currents, maintaining the charge current and the charging time, $\mathrm{C} / 2$, for $2.5 \mathrm{~h}$.

Figure 3 shows an electrode that was impregnated with a pulse current (CP2 and $\mathrm{CP} 3$ ), delivering over $80 \%$ of the 


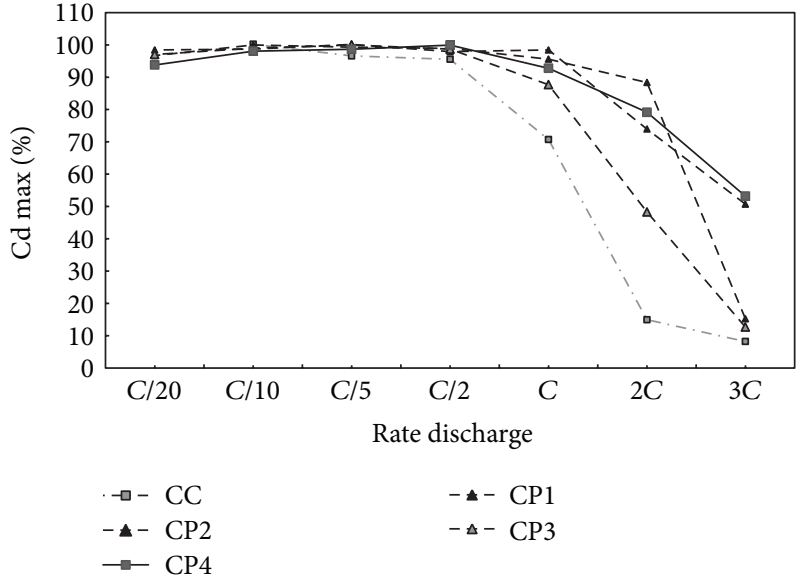

FIGURE 3: Discharge capacity versus discharge current rate.

maximum capacity at a $2 \mathrm{C}$ rate of discharge. This means that this type of electrode provides a large amount of energy in a few seconds. As a result, the utilization of active material was considerably improved and the electrode polarization resistance decreased after impregnating the electrode with pulse current.

Table 1 shows that the loading of all electrodes is similar but the utilization rate (discharge capacity/theoretical capacity) of the nickel electrode impregnated with continuous current is much lower than that of the other electrodes.

In some cases, a mass of active material was deposited but was not used in the discharge reactions.

For other electrodes, the number of exchanged electrons per metal atom (NEE) was greater than $1\left(>289 \mathrm{mAhg}^{-1}\right)$, a number that may be surprising. Since the reaction $\mathrm{Ni}(\mathrm{OH})_{2} / \mathrm{NiOOH}$ involves the exchange of a unique electron, this observation comes from the fact that upon extended charging, $125 \%$ of the initial capacity assuming a number of NEE of $1, \gamma-\mathrm{NiOOH}$ oxidized phase formation occurs and is characterized by an oxidation degree between 3.3 and 3.6 due to the presence of $\mathrm{Ni}^{+4}$ ions [38].

Audemer et al. [39] showed that the electrochemical capacity increases as the particle size decreases. A critical size seems to appear around $250 \AA$, which corresponds to the best electrochemically active hydroxide. When the particle size is small, the surface/volume ratio is high, so the amount of adsorbed water is larger.

The electrode impregnated with a high-frequency pulse current shows the best performance of all electrodes tested. This situation can be directly related to the morphology of the deposit of active material as evidenced in previous work [40].

A low current $(\mathrm{C} / 20)$ of discharge produces self-discharge because there are parallel reactions [41].

3.3. Influence of Current Pulse on Discharge Capacity. The optimum electrode was chosen from different electrodes impregnated with different current frequencies. The cyclability and discharge capacity were taken into account as parameters by selection. These two parameters are very

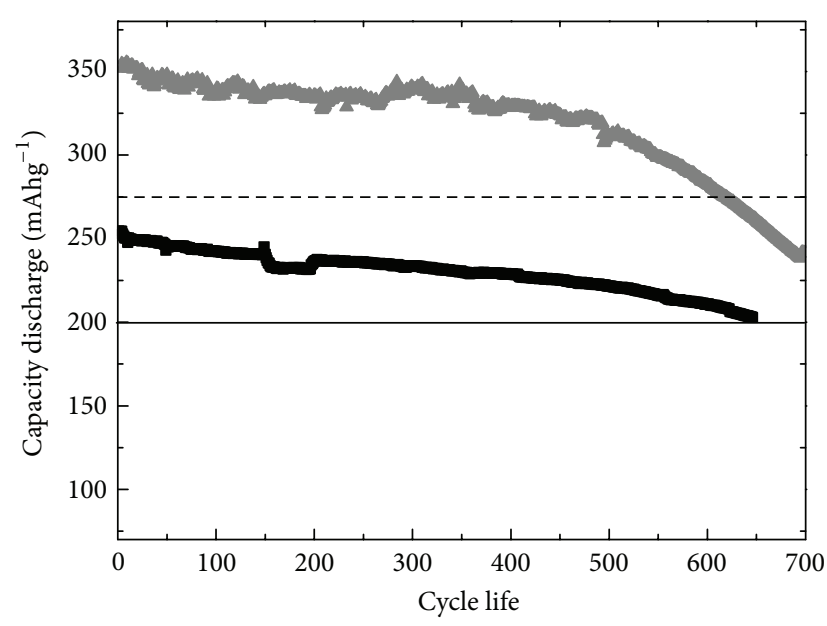

Electrode CP4

FIGURE 4: Variation of the discharge capacity versus number of cycles.

important in the performance of batteries. The electrode CP3 is one of the best electrodes and was selected to be compared with electrode CC.

So far, no relationship has been found between frequency and electrochemical performance.

3.4. Cycle Life. Figure 4 shows the cycle lives of electrodes $\mathrm{CP} 3$ and CC. The results indicate that the cycle lives of the electrodes are related to the kind of technique used: the longest cycle life was achieved for the electrode built with a train of pulses. For example, after 300 charge-discharge cycles (100\% depth of discharge, DOD), the electrode CP3 still kept $96 \%$ of the initial capacity, which was much higher than that of any other electrode.

Each cycle begins with 150 min charge at a $\mathrm{C} / 2$ rate followed by a $\mathrm{C} / 2$ rate discharge to $0.2 \mathrm{~V}$ versus $\mathrm{Hg} / \mathrm{HgOss}$.

A stable discharge capacity is observed with cycle life until cycle 500, after which the capacity drops sharply. One of the reasons is electrode swelling, which changes the electrode thickness after several numbers of cycles. Therefore, the cycle life of the electrode can be correlated with the electrode expansion: the greater the electrode swelling is, the faster the capacity decay of the electrode results.

3.5. Physical Properties of Nickel Hydroxide. Zhang and HouTian have performed the impregnation by applying intermittent currents, ON:OFF pulses, with the aim of reducing the activation and polarization by concentrating polarization on the cathode. In this way, smaller active material particles were formed, thus increasing the active surface area of the electrode and achieving greater use of the deposited material [31].

Photomicrographs (Figures 5(a) and 5(b)) show, with different magnifications, the morphology of the porous substrate prior to impregnation. 


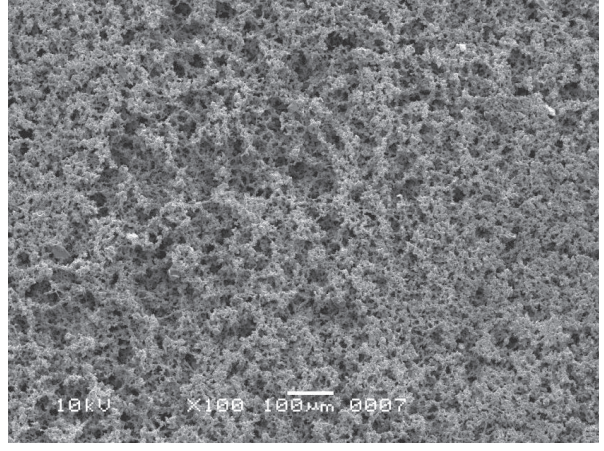

(a)

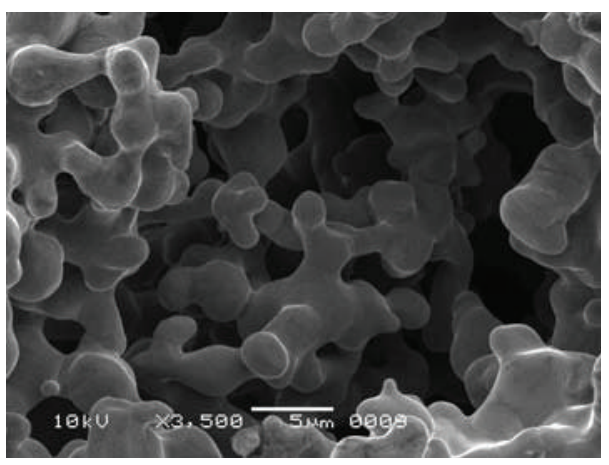

(b)

FIGURE 5: Sintered nickel plate (a) 100x (b) 3500x.

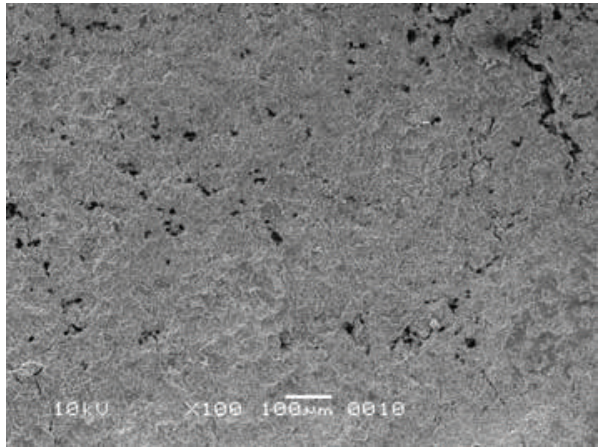

(a)

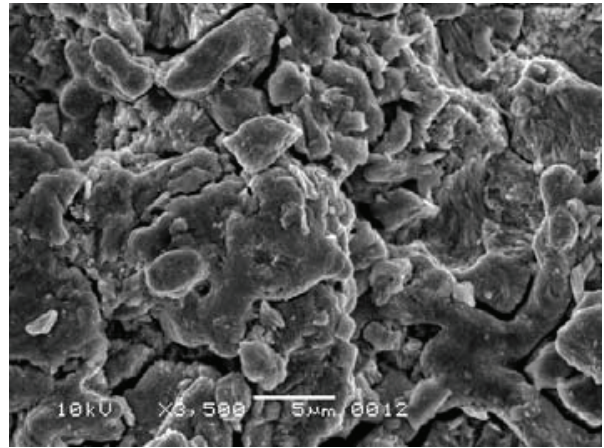

(b)

FIGURE 6: SEM micrographs of the electrode surface (CC), with nickel hydroxide as the active material; (a) 120x and (b) 3500x.

TABLE 2: Chemical properties of different types of electrode samples.

\begin{tabular}{lcc}
\hline & \multicolumn{3}{c}{ Analysis (\% w/w) } \\
& $\mathrm{Ni}$ & $\mathrm{Co}$ \\
\hline Electrode CC & 41.63 & 04.61 \\
Electrode CP3 & 30.06 & 03.20 \\
\hline
\end{tabular}

The morphology of the deposited material is shown in Figures 6 and 7.

The deposits made by applying a continuous current Figure 6(a) cover the total nickel mesh and are more compact than those deposited through a train of pulses (Figure 7(a)).

Figure 6 shows that the material is compact and its composition corresponds to the active material that contains $\mathrm{Ni}$ and Co (see Table 2).

The loading $\left(\mathrm{gcm}^{-3}\right)$ from sample CC (continuous current) was $10 \%$ larger than that of sample CP3 (pulse current). The surface morphology of the deposited material in the first sample is homogeneous and compact. Although we achieve a greater loading, this value does not guarantee a better nickel electrode capacity.

In the case of pulse-current deposition, the active material is deposited along the shape of the porous substrate and leaves visible gaps or pores. This leads to an increased deposition of the surface active material, achieving a higher utilization rate. It can also be observed that the deposited material has a spongy appearance, generating an electrode with a larger active surface area and smaller particle size.

Table 2 presents the EDS results of both nickel electrodes with cobalt added. The cobalt present in the active material of the electrode was in the same proportion as in the impregnation solution.

\section{Conclusions}

All electrodes that were electrochemically impregnated with pulse current showed optimum capacity, similar to loading values found in the literature, with the active material producing a larger active surface area. When the impregnation current is continuous, the active material forms a homogeneous and compact surface with optimum loading but poor performance during discharge. Furthermore, the electrodes that were impregnated with different pulse currents produce loading similar to that of the electrodes impregnated with continuous current, although their active material is deposited following the shape of the porous substrate. This type of deposition produces a larger active surface area that has the highest utilization percentage. The particle size influences the electrochemical performance. When the particle size decreases, the amount of adsorbed water molecules on the surface of the particles increases. This 


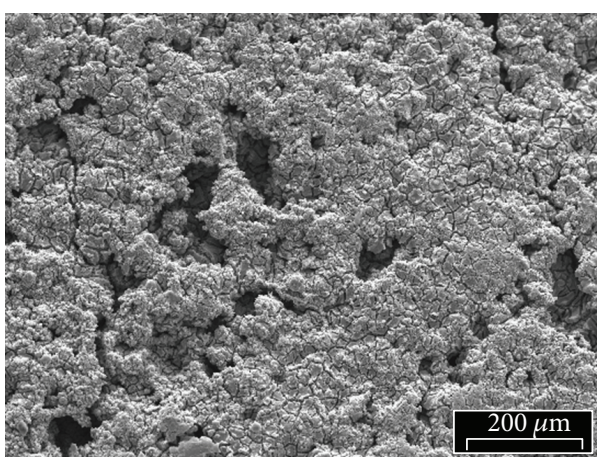

(a)

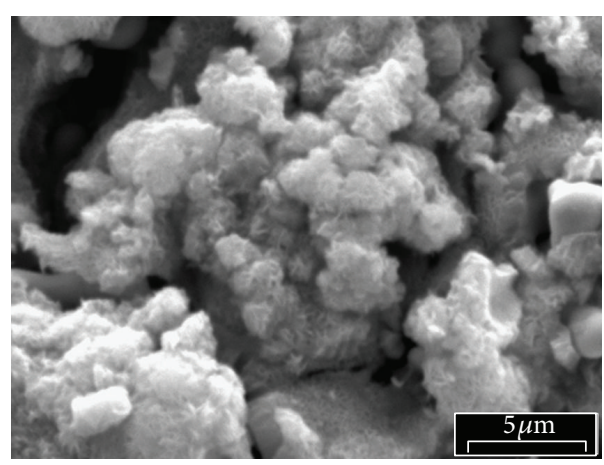

(b)

FIGURE 7: SEM micrographs of the electrode surface (CP3), with nickel hydroxide as the active material; (a) 120x and (b) 3500x.

surface water is thought to improve nickel hydroxide particle wettability, thus resulting in an enhanced proton transport within the active mass during the charge-discharge process and a better utilization of the electrode material.

\section{Acknowledgments}

This work was supported by CONICET, Consejo Nacional de Investigaciones Científicas y Técnicas of Argentina; Agencia Nacional de Promoción Científica y Tecnológica; CIC, Comisión de Investigaciones Científica de la Provincia de Buenos Aires; and Universidad Nacional de La Plata.

\section{References}

[1] Z. H. Liang, Y. J. Zhu, and X. L. Hu, “ $\beta$-nickel hydroxide nanosheets and their thermal decomposition to nickel oxide nanosheets," Journal of Physical Chemistry B, vol. 108, no. 11, pp. 3488-3491, 2004.

[2] X. He, J. Li, H. Cheng, C. Jiang, and C. Wan, "Controlled crystallization and granulation of nano-scale $\beta-\mathrm{Ni}(\mathrm{OH})_{2}$ cathode materials for high power Ni-MH batteries," Journal of Power Sources, vol. 152, no. 1-2, pp. 285-290, 2005.

[3] G. Garaventta, M. Becker, D. Barsellini, A. Visintin, and W. Triaca, "Performance of the SAC-C satellite electricity storage system," International Journal of Hydrogen Energy, vol. 37, no. 7, pp. 5706-5709, 2012.

[4] M. Dixit, P. Vishnu Kamath, and J. Gopalakrishnan, "Zincsubstituted $\alpha$-nickel hydroxide as an electrode material for alkaline secondary cells," Journal of the Electrochemical Society, vol. 146, no. 1, pp. 79-82, 1999.

[5] J. L. Weininger, On the Nickel Electrode, The Electrochemical Society, Pennington, NJ, USA, 1982.

[6] D. F. Pickett and J. T. Maloy, "Microelectrode studies of electrochemically coprecipitated cobalt hydroxide in nickel hydroxide electrodes," Journal of the Electrochemical Society, vol. 125, no. 7, pp. 1026-1032, 1978.

[7] Y. J. Kim, A. Visintin, S. Srinivasan, and A. J. Appleby, "Microcalorimetric study of self-discharge of nickel hydroxide electrode," Journal of the Electrochemical Society, vol. 139, no. 2, pp. 351-354, 1992.

[8] A. Visintin, S. Srinivasan, A. J. Appleby, and H. Lim, "Microcalorimetry Study of $\mathrm{Ni} / \mathrm{H}_{2}$ Battery Self-Discharge Mechanism,"
Journal of The Electrochemical Society, vol. 139, no. 4, pp. 985988, 1992.

[9] Z. Mao, A. Visintin, S. Srinivasan, A. J. Appleby, and H. S. Lim, "Microcalorimetric study of the self-discharge of the $\mathrm{NiOOH} / \mathrm{Ni}(\mathrm{OH})_{2}$ electrode in a hydrogen environment," Journal of Applied Electrochemistry, vol. 22, no. 5, pp. 409-414, 1992.

[10] C. C. Yang, "Synthesis and characterization of active materials of $\mathrm{Ni}(\mathrm{OH})_{2}$ powders," International Journal of Hydrogen Energy, vol. 27, no. 10, pp. 1071-1081, 2002.

[11] A. H. Zimmerman and P. K. Effa, "Discharge kinetics of the nickel electrode," Journal of the Electrochemical Society, vol. 131, no. 4, pp. 709-713, 1984.

[12] R. D. Armstrong, G. W. D. Briggs, and E. A. Charles, "Some effects of the addition of cobalt to the nickel hydroxide electrode "' Journal of Applied Electrochemistry, vol. 18, no. 2, pp. 215-219, 1988.

[13] A. Yuan, S. Cheng, J. Zhang, and C. Cao, "Effects of metallic cobalt addition on the performance of pasted nickel electrodes," Journal of Power Sources, vol. 77, no. 2, pp. 178-182, 1999.

[14] H. Bode, K. Dehmelt, and J. Witte, "Zur kenntnis der nickelhydroxidelektrode-I. Über das nickel (II)-hydroxidhydrat," Electrochimica Acta, vol. 11, no. 8, pp. 1079-1087, 1966.

[15] M. B. J. G. Freitas, "Nickel hydroxide powder for NiO·OH/ $\mathrm{Ni}(\mathrm{OH})_{2}$ electrodes of the alkaline batteries," Journal of Power Sources, vol. 93, no. 1-2, pp. 163-173, 2001.

[16] D. L. Britton, "Progress in development of lightweight nickel electrode for aerospace application," NASA Technical Memorandum 105591, 1992.

[17] E. J. McHenry, "Electrochemical precipitation of $\mathrm{Ni}(\mathrm{OH})_{2}$ in porous electrode," Journal of Electrochemical Technology, vol. 5, p. $275,1967$.

[18] K. C. Ho and J. Jorne, "Electrochemical impregnation of nickel hydroxide. Flow-through vs stagnant electrodes," Journal of the Electrochemical Society, vol. 137, no. 1, pp. 149-158, 1990.

[19] M. Dixit, P. V. Kamath, V. G. Kumar, N. Munichandraiah, and A. K. Shukla, "An electrochemically impregnated sintered-nickel electrode," Journal of Power Sources, vol. 63, no. 2, pp. 167-171, 1996.

[20] R. S. Jayashree and P. V. Kamath, "Nickel hydroxide electrodeposition from nickel nitrate solutions: mechanistic studies," Journal of Power Sources, vol. 93, no. 1-2, pp. 273-278, 2001.

[21] D. A. Corrigan, "Catalysis of the oxygen evolution reaction by iron impurities in thin film nickel oxide electrodes," Journal of the Electrochemical Society, vol. 134, no. 2, pp. 377-384, 1987. 
[22] K. C. Ho and I. Jome, "Electrochemical impregnation of nickel hydroxide flow-through vs. stagnant electrodes," Journal of The Electrochemical Society, vol. 137, no. 1, pp. 149-158, 1990.

[23] R. S. Jayashree and P. Vishnu Kamath, "Factors governing the electrochemical synthesis of $\alpha$-nickel (II) hydroxide," Journal of Applied Electrochemistry, vol. 29, no. 4, pp. 449-454, 1999.

[24] D. M. Constantin, E. M. Rus, L. Oniciu, and L. Ghergari, "The influence of some additives on the electrochemical behaviour of sintered nickel electrodes in alkaline electrolyte," Journal of Power Sources, vol. 74, no. 2, pp. 188-197, 1998.

[25] F. Portemer, A. Delahaye-Vidal, and M. Figlarz, "Characterization of active material deposited at the nickel hydroxide electrode by electrochemical impregnation," Journal of the Electrochemical Society, vol. 139, no. 3, pp. 671-678, 1992.

[26] A. Yuan, S. Cheng, J. Zhang, and C. Cao, "Effects of metallic cobalt addition on the performance of pasted nickel electrodes," Journal of Power Sources, vol. 77, no. 2, pp. 178-182, 1999.

[27] C. Sigala, A. Verbaere, J. L. Mansot, D. Guyomard, Y. Piffard, and M. Tournoux, "The Cr-substituted spinel Mn oxides $\mathrm{LiCryMn}_{2}-$ $\mathrm{yO}_{4}(0 \leq y \leq 1)$ : rietveld Analysis of the Structure Modifications Induced by the Electrochemical Lithium Deintercalation," Journal of Solid State Chemistry, vol. 132, no. 2, pp. 372-381, 1997.

[28] M. Oshitani, H. Yufu, K. Takashima, S. Tsuji, and Y. Matsumaru, "Development of a pasted nickel electrode with high active material utilization," Journal of the Electrochemical Society, vol. 136, no. 6, pp. 1590-1593, 1989.

[29] V. Pralog, A. Delahaye-Vidal, B. Beaudoin, B. Gerand, J. B. Leriche, and J. M. Tarascon, "Electrochemical behavior of cobalt hydroxide used as additive in the nickel hydroxide electrode," Journal of The Electrochemical Society, vol. 147, no. 4, pp. 13061313, 2000.

[30] M. Oshitani, T. Takayama, K. Takashima, and S. Tsuji, "A study on the swelling of a sintered nickel hydroxide electrode," Journal of Applied Electrochemistry, vol. 16, no. 3, pp. 403-412, 1986.

[31] T. N. Zhang and P. V. Hou-Tian, "The effect of cobalt on the electrochemical performance of $\beta$-nickel hydroxide electrodes," Electrochimica Acta, vol. 53, no. 28, pp. 8324-8331, 2008.

[32] M. Oshitani, H. Yufu, K. Takashima, S. Tsuji, and Y. Matsumaru, "Development of a pasted nickel electrode with high active material utilization," Journal of the Electrochemical Society, vol. 136, no. 6, pp. 1590-1593, 1989.

[33] T. Takamura, T. Shirogami, and T. Nakamura, "Electrolytic impregnation of active material sintered nickel oxide to nickel substrate," Denki Kagaku, vol. 42, p. 582, 1974.

[34] W. B. Zhang and L. Houtian, in Proceedings of the 35th International Society of Electrochemistry Meeting, vol. 6077 of Extended Abstracts, p. 102, Berkeley, Calif, USA, 1984.

[35] W. B. Zhang, Fudan Journal, vol. 17, no. 3, p. 112, 1978.

[36] M. Dixit, P. V. Kamath, V. G. Kumar, N. Munichandraiah, and A. K. Shukla, "An electrochemically impregnated sintered-nickel electrode," Journal of Power Sources, vol. 63, no. 2, pp. 167-171, 1996.

[37] C. Bleser, "Positive electrode processing for Hughes NiH2 cells," in Proceedings of the Goddard Space Flight Center Battery Workshop, p. 471, 1981.

[38] D. A. Corrigan and S. L. Knight, "Electrochemical and spectroscopic evidence on the participation of quadrivalent nickel in the nickel hydroxide redox reaction," Journal of the Electrochemical Society, vol. 136, no. 3, pp. 613-619, 1989.

[39] A. Audemer, A. Delahaye, R. Farhi, N. Sac-Epée, and J. M. Tarascon, "Electrochemical and Raman studies of beta-type nickel hydroxides Nil-xCox $(\mathrm{OH}) 2$ electrode materials," Journal of the Electrochemical Society, vol. 144, no. 8, pp. 2614-2620, 1997.

[40] M. Ortiz, D. Becker, G. Garaventta, A. Visintin, E. B. Castro, and S. G. Real, "Dynamic monitoring of structural changes in nickel hydroxide electrodes during discharge in batteries," Electrochimica Acta, vol. 56, no. 23, pp. 7946-7954, 2011.

[41] M. Paszkiewicz and I. Walas, "The potentiodynamic investigations of the overcharge and self-discharge of nickel hydroxide electrode," Electrochimica Acta, vol. 24, no. 6, pp. 629-631, 1979. 


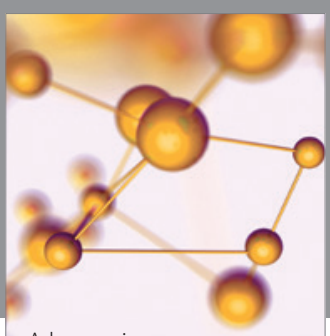

Physical Chemistry
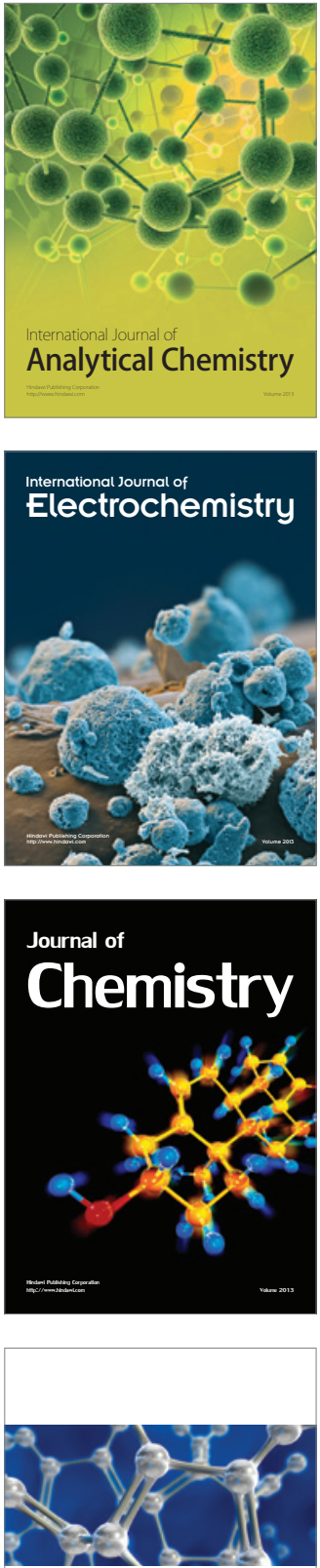

ISRN

Inorganic Chemistry

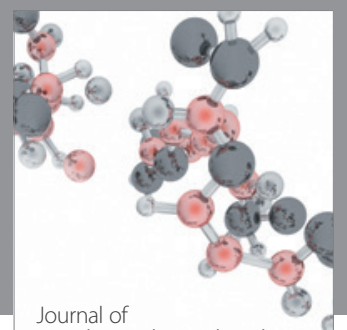

Analytical Methods in Chemistry

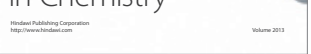

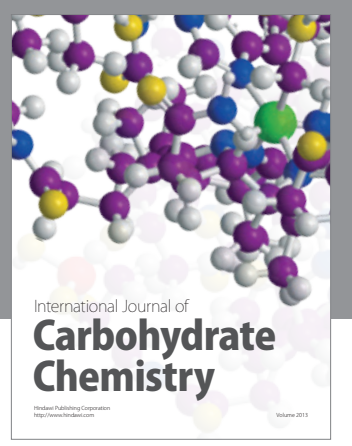
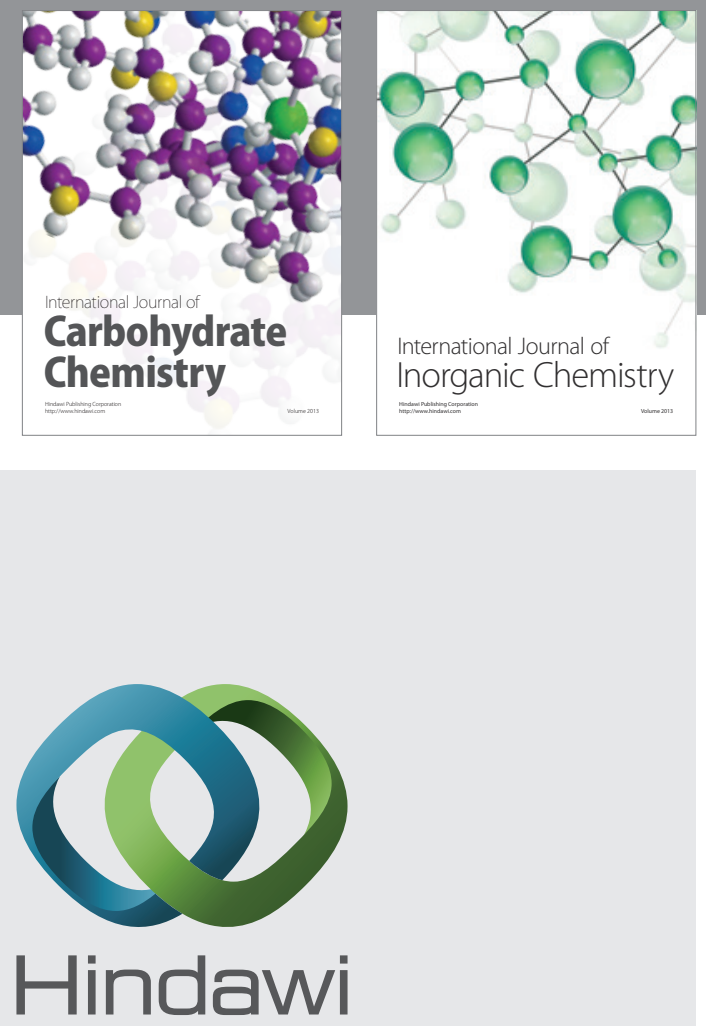

Submit your manuscripts at http://www.hindawi.com
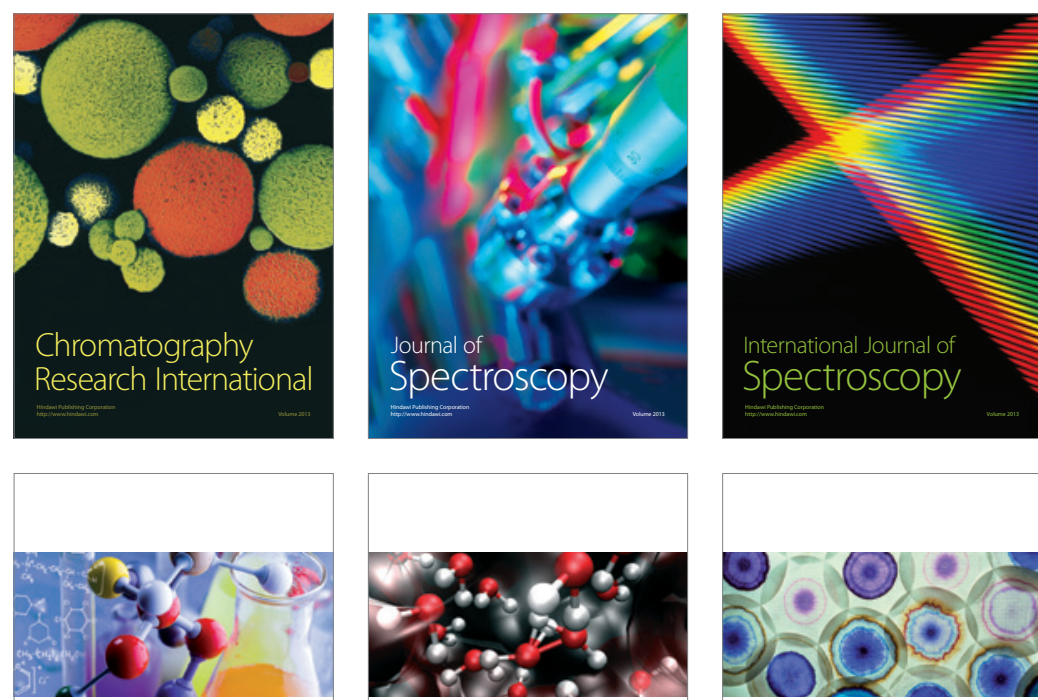

ISRN

ISRN

Organic Chemistry

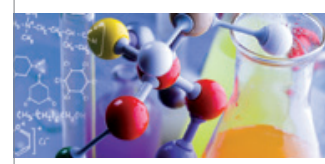

Physical Chemistry

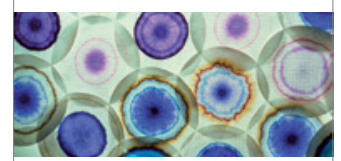

ISRN

Chromatography

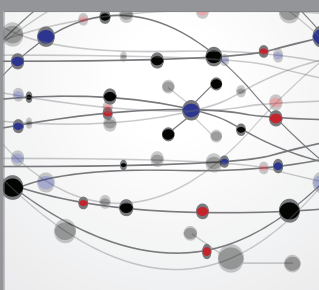

The Scientific World Journal
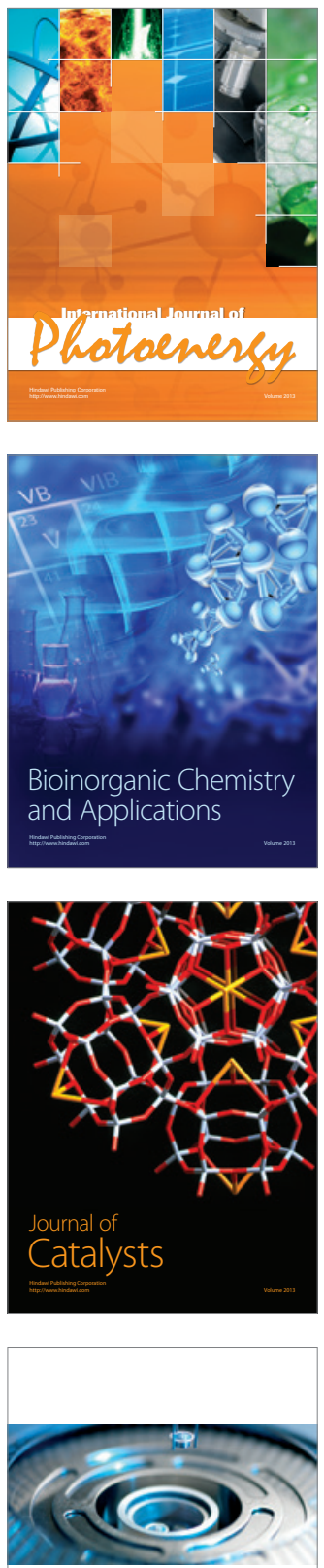

ISRN

Analytical

Chemistry 


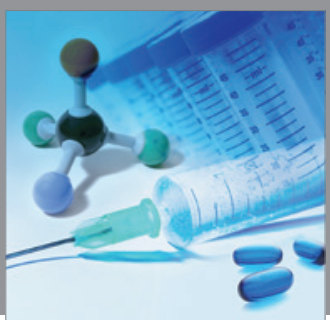

International Journal of

Medicinal Chemistry

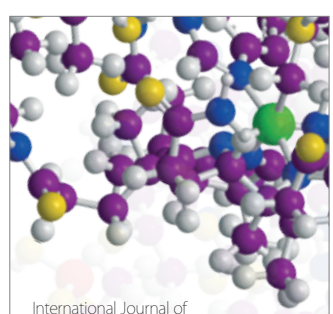

Carbohydrate Chemistry

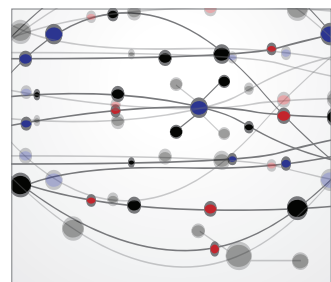

The Scientific World Journal
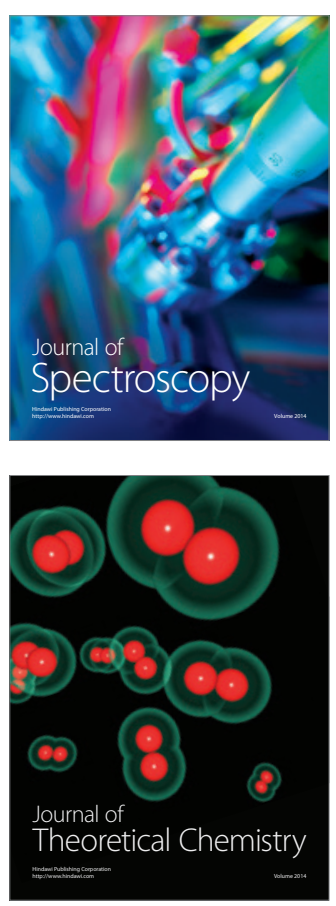
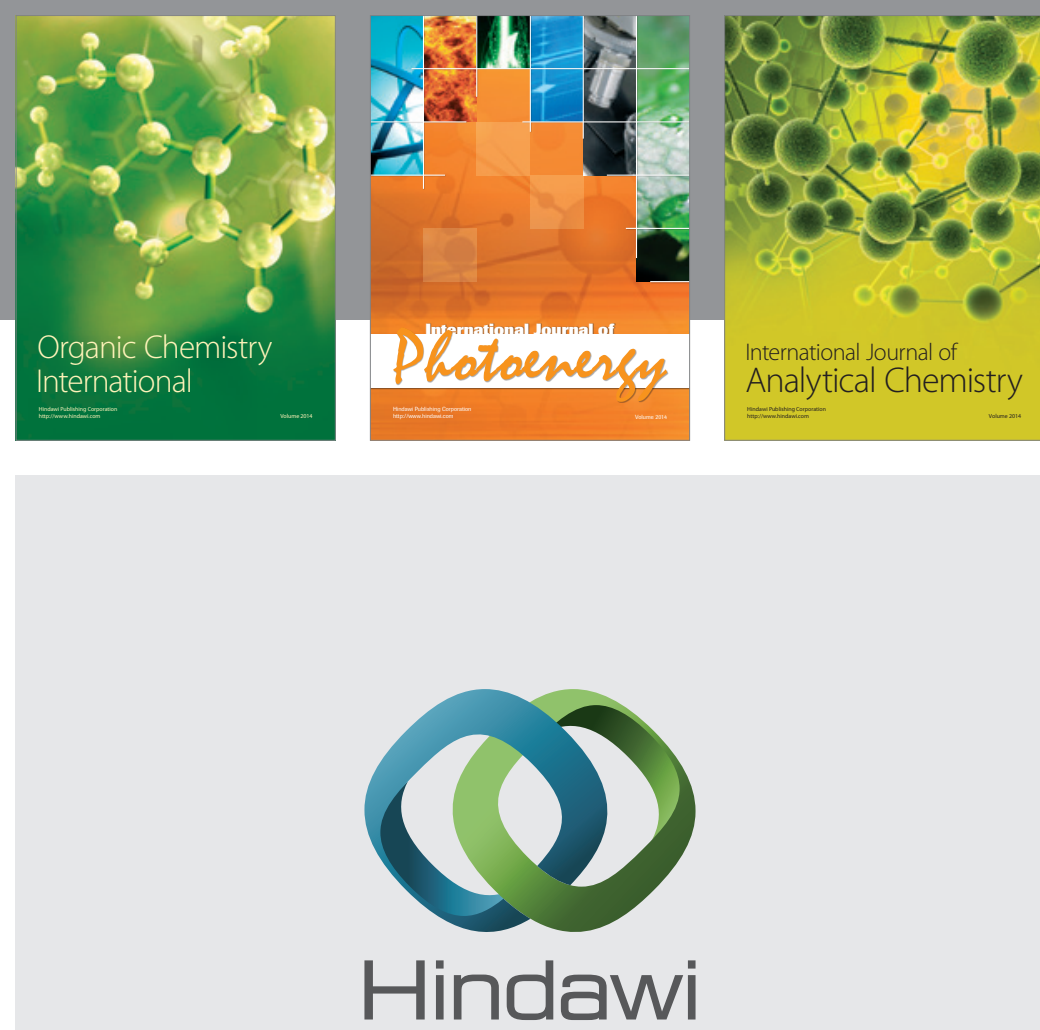

Submit your manuscripts at

http://www.hindawi.com
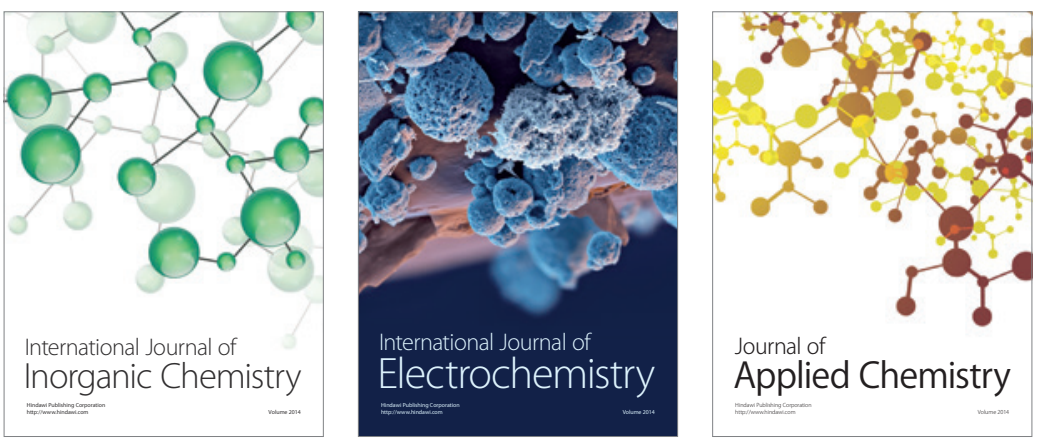

Journal of

Applied Chemistry
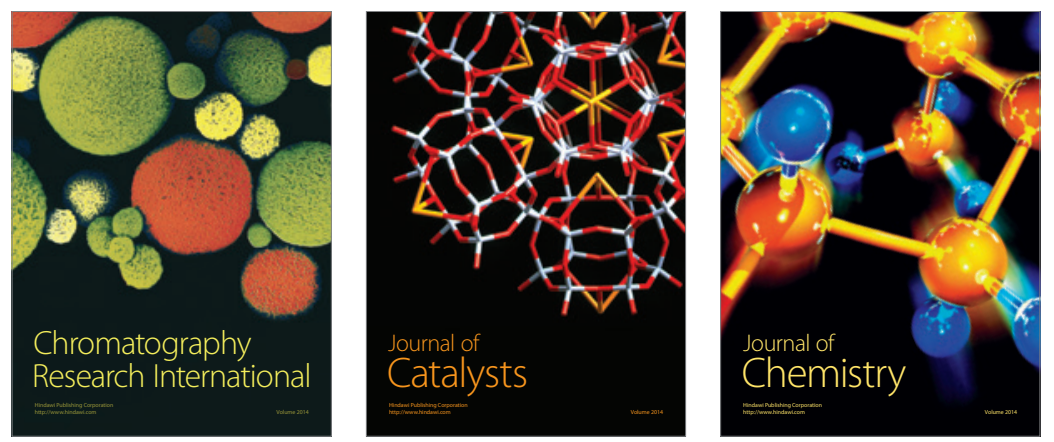
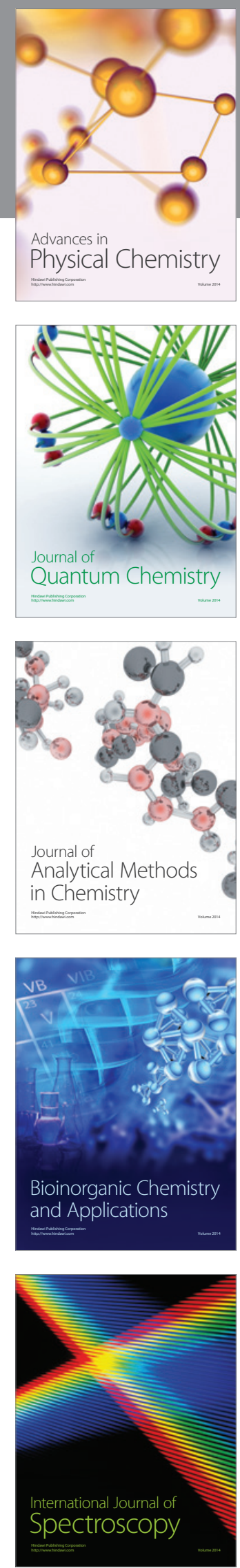